\title{
Compatibilizing Effect of Phenoxy on Immiscible Poly(butylene terephthalate)/Poly(methyl methacrylate) Blends
}

\author{
Won Ho Jo, Joo Yong KiM, and Moo Sung LEE* \\ Department of Fiber and Polymer Science, Seoul National University, \\ Seoul 151-742, Korea \\ * Department of Textile Engineering, Chonnam National University, \\ Kwang Ju 500-757, Korea
}

(Received August 4, 1993)

\begin{abstract}
The compatibilizing effect of poly(hydroxy ether of Bisphenol A) (Phenoxy) on the immiscible poly(butylene terephthalate) (PBT)/poly(methyl methacrylate) (PMMA) blends was examined by differential scanning calorimetry and scanning electron miscoscopy. It was found that the Phenoxy, which was miscible with each of the other blend components, solubilized the two immiscible polymers at its loading levels greater than $50 \mathrm{wt} \%$. When a small amount of Phenoxy was added to the immiscible blends, the morphology changed into more regular and finer dispersion. The tensile properties are increased as the content of Phenoxy increases, although the improvement is limited. From the morphology and mechanical properties, it is concluded that Phenoxy plays an appropriate role in compatibilizing the immiscible blends of PBT and PMMA.
\end{abstract}

KEY WORDS Polymer Blends / Compatibilizer / Phenoxy / Poly(butylene terephthalate)/Poly(methyl methacrylate) /

Polymer blends give an efficient way of formulating new materials with tailored properties. They may be divided into two different categories, the so-called miscible blends in which the component polymers exist in a single homogeneous phase and the immiscible ones in which the components exist in two distinct separated phases. Generally, the former offers various advantages over the latter. Since the entropy gain upon mixing of polymers is negligibly small while the enthalpy of mixing is usually positive unless a specific interaction is present, the formation of miscible blends is relatively a rare phenomenon. ${ }^{1,2}$ To obtain desirable properties there have been efforts to increase the compatibility of otherwise immiscible blends. ${ }^{3}$

The addition of a compatibilizer into an immiscible blend is a potential method to enhance the properties of the blends. Many immiscible polymer pairs have been compatibiliz- ed by the addition of a third component such as block or graft copolymers. ${ }^{4,5}$ The copolymers facilitate mixing by dramatically lowering the interfacial tension between the immiscible phases, when added in small amounts to the immiscible polymer pair. Thus the use of those copolymers has led to the design of polymer blends with remarkable versatile mechanical properties. The details of various compatibilizers for polymer alloys have been well reviewed in an excellent literature. ${ }^{6}$ As another candidate, a third homopolymer which is miscible with each component of immiscible blends may be used for the compatibilization of immiscible blends. The prerequisite for that case is that the third is miscible with both polymers, but both polymers are immiscible with each other. Several papers have been published concerning the miscibility of ternary polymer blends. ${ }^{7-13}$

Although poly(butylene terephthalate) (PBT) and poly(methyl methacrylate) (PMMA) are 
immiscible, ${ }^{14}$ both polymers are miscible with poly(hydroxy ether of Bisphenol A) (Phenoxy). ${ }^{15,16}$ Therefore, one can expect that Phenoxy acts as a compatibilizer for the immiscible blends of PBT and PMMA.

The object of this study is to ascertain the compatibilizing effect of Phenoxy by examining the variation of the morphological structure and glass transition temperature with the Phenoxy content in the PBT/Phenoxy/PMMA ternaries. In addition, the tensile properties of the ternary blends are measured and discussed in terms of the compatibilizing effect of Phenoxy.

\section{EXPERIMENTAL}

The polymers used in this study were commercial products and were used as received without further purification. The characteristics of the polymers are summarized in Table I.

The pre-dried polymers were melt-mixed in various compositions by an extruder (Brabender Plasticoder) at $240^{\circ} \mathrm{C}$ for 5 minutes. Before blending, the extruder was flushed with nitrogen to avoid the potential degradation of component polymers. The mixtures were granulated as pellets and dried again in a vacuum oven at $110^{\circ} \mathrm{C}$ for a day to avoid hydrolytic degradation. The test specimens of the dimensions specified in ASTMD-638 were prepared by a compression moulding technique using an injection moulder. The moulding temperature was $240^{\circ} \mathrm{C}$. The polymer components in the blend did not exhibit any thermal degradation and oxidation at this blending conditions.

Thermal analysis was performed on a $\mathrm{Du}$ Pont 910 differential scanning calorimeter
(DSC) equipped with a mechanical cooling accessory. For the measurement of glass transition temperature $\left(T_{\mathrm{g}}\right)$, the blend samples were first maintained at $250^{\circ} \mathrm{C}$ for 3 minutes to eliminate thermal history, quenched to $-70^{\circ} \mathrm{C}$, and then heated at a heating rate of $20^{\circ} \mathrm{C} \mathrm{min}^{-1}$. The glass transition temperature was taken as the midpoint of the heat capacity change in the second scan. When annealing was required, the samples were annealed at $60^{\circ} \mathrm{C}$ for 200 hours. In this case, the first scan data were accepted. As supplimentary data, the dynamic mechanical properties as a function of temperature were measured at a frequency of $10 \mathrm{~Hz}$ using a Rheometric Mechanical Spectrometer (RMS 800). Heating rate was $5^{\circ} \mathrm{C} \mathrm{min}^{-1}$.

The morphology of the blends was observed with a scanning electron microscope (SEM, JEOL JSM-T200) operating at $25 \mathrm{kV}$. Blend samples were fractured at liquid nitrogen temperature. To remove the minor phase in the ternaries, a solvent extraction method was used.

Tensile properties were measured on an Instron 4201 tensile tester at a crosshead speed of $10 \mathrm{~min} \mathrm{~min}^{-1}$. Test was conducted at room temperature, below $T_{\mathrm{g}}$ 's of the blends. Ten specimens were tested on each blend composition, and average values were taken as experimental data.

\section{RESULTS AND DISCUSSION}

\section{Miscibility of Binary Blends}

The existence of a single and compositiondependent $T_{\mathrm{g}}$ between those of pure components is a widely used criterion in determining the miscibility of a polymer blend. Figure 1

Table I. Polymer characteristics

\begin{tabular}{lccrc}
\hline \multicolumn{1}{c}{ Polymer } & Abbreviation & Source & $\bar{M}_{w}$ & $T_{\mathbf{g}} /{ }^{\circ} \mathrm{C}$ \\
\hline Poly(butylene terephthalate) & PBT & Lucky Co. & 94000 & 34 \\
Poly(hydroxy ether of bisphenol A) & Phenoxy & Union Carbide Co. & 82000 & 96 \\
Poly(methyl methacrylate) & PMMA & Lucky Co. & 74000 & 115 \\
\hline
\end{tabular}




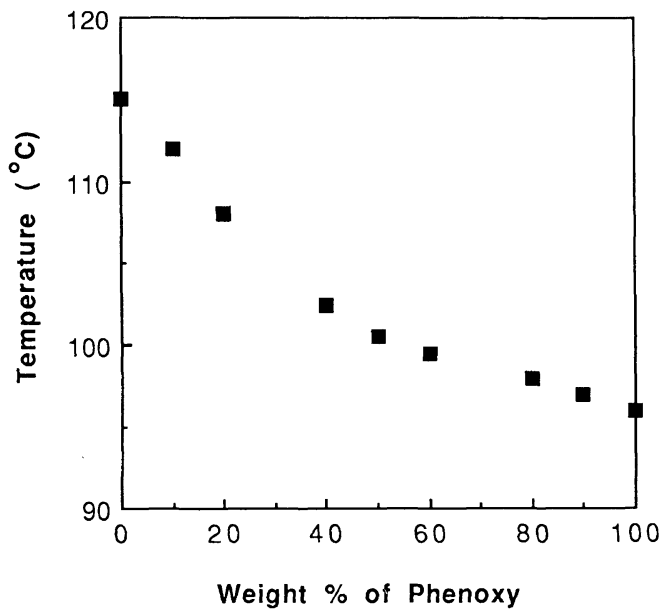

Figure 1. Glass transition temperatures of Phenoxy/ PMMA blends.

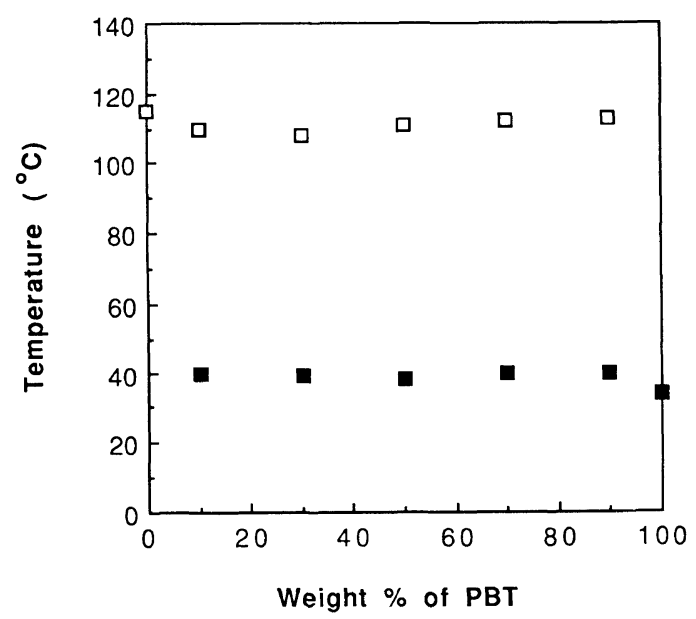

Figure 2. Glass transition temperatures of PBT/PMMA blends: ( $\square$ ) PMMA-phase; ( $\square$ ) PBT-phase.

shows that the blends of Phenoxy and PMMA have single composition-dependent $T_{\mathrm{g}}$ 's between those of Phenoxy and PMMA, indicating a single phase nature. All the blends were clear in both the solid and melt states up to $\mathrm{ca} .300^{\circ} \mathrm{C}$. However, as shown in Figure 2, two distinct $T_{\mathrm{g}}$ 's corresponding to those of the blend components are found at all compositions of PBT/PMMA blends. This indicates the existence of two phases in the blends; the high $T_{\mathrm{g}}$ corresponds to a phase composed principally

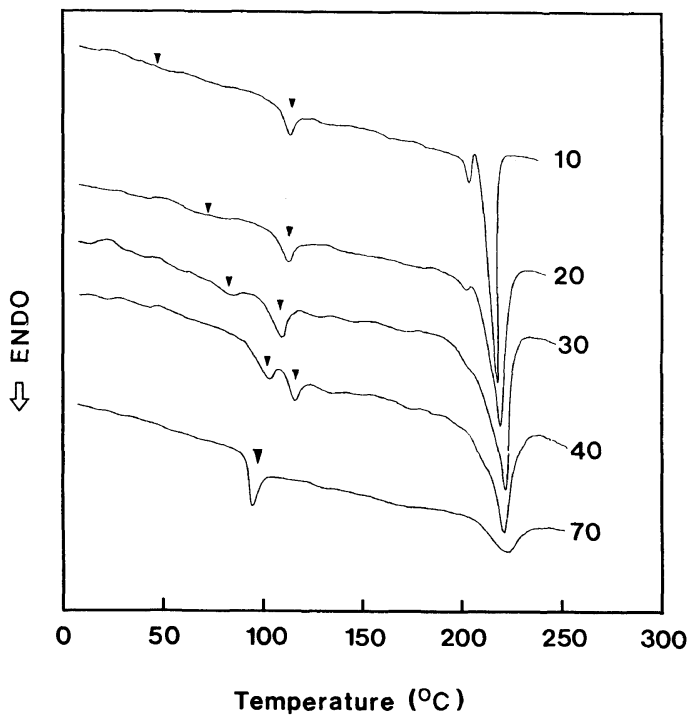

Figure 3. Representative DSC thermograms of ternary blends with a PBT/PMMA ratio of $1 / 1$.

of PMMA, while the lower $T_{\mathrm{g}}$ corresponds to the PBT rich phase. All the blends of PBT/PMMA were opaque in the melt state. Although not examined in this study, PBT/Phenoxy blends have been well known to be miscible over the entire composition range. ${ }^{15,17}$ In summary, Phenoxy is miscible with both PBT and PMMA, which are immiscible with each other. Therefore, we can expect that Phenoxy acts as a compatibilizer for the immiscible blends of PBT and PMMA.

\section{Phase Behavior of Ternary Blends}

In judging the miscibility of ternary blends from the $T_{\mathrm{g}}$ measurement, one should consider the possibility that, depending on composition and the $T_{\mathrm{g}}$ of the blend components, the single $T_{\mathrm{g}}$ observed in the ternaries may not be the result of the true miscibility but of an overlap of the $T_{\mathrm{g}}$ 's of the binaries. But, the calorimetric method with the aid of physical aging provides a valid experimental technique to determine the miscibility of ternary blends even when the $T_{\mathrm{g}}$ 's of the binaries are very close to each other. The procedure relies on the phenomenon of enthalpy recovery in physically aged glassy 
blends. ${ }^{18,19}$

Figure 3 shows the representative DSC thermograms of PBT/Phenoxy/PMMA ternary blends having the PBT/PMMA ratio of $1 / 1$. All the samples were annealed at $60^{\circ} \mathrm{C}$ for 200 hours. Numbers at each thermogram indicate the content of Phenoxy with respect to the total weight of the blended polymers. The thermograms show two different enthalpy recovery peaks in the range of $40-140^{\circ} \mathrm{C}$. The lower $T_{\mathrm{g}}$ corresponding to PBT-rich phase increases with an increase of the Phenoxy content, whereas the higher $T_{\mathrm{g}}$ of PMMA-rich phase is almost independent of the Phenoxy content. The peaks at near $220^{\circ} \mathrm{C}$ correspond to the melting endotherms of PBT in the ternaries. Although their magnitudes decrease with increasing Phenoxy contents, their position are not affected by the composition of Phenoxy.

In Figure 4, the results from the $T_{\mathrm{g}}$ measurement are shown as a function of the weight fraction of Phenoxy at constant PBT/PMMA ratios. The axis of abscissa is expressed as parts by weight Phenoxy per 100 parts of the PBT/PMMA mixtures. Two distinct $T_{\mathrm{g}}$ 's are observed at the low loading level of Phenoxy, indicating that the blends are phase-separated into two distinct phases, PMMA-rich (higher $T_{\mathrm{g}}$ ) and PBT-rich (lower $T_{\mathrm{g}}$ ) phases. However, when sufficient Phenoxy above $c a .50 \mathrm{wt} \%$ is added, the ternaries have the single $T_{\mathrm{g}}$ 's characteristic of a miscible system. The difference in the $T_{\mathrm{g}}$ variation of each phase with the Phenoxy content results from the difference in the dissolution of Phenoxy in each phase. Assuming that the two distinct phases are only binary mixtures of PMMA/Phenoxy and of PBT/Phenoxy, it is clear that Phenoxy is more solubilized in the PBT-rich phase, because the elevation of $T_{\mathrm{g}}$ 's of PBT/Phenoxy phase is more significant than the depression of $T_{\mathrm{g}}$ 's of PMMA/Phenoxy phase. This indicates that Phenoxy is more attractive with PBT than with PMMA. Jo and Lee reported that the interaction energy
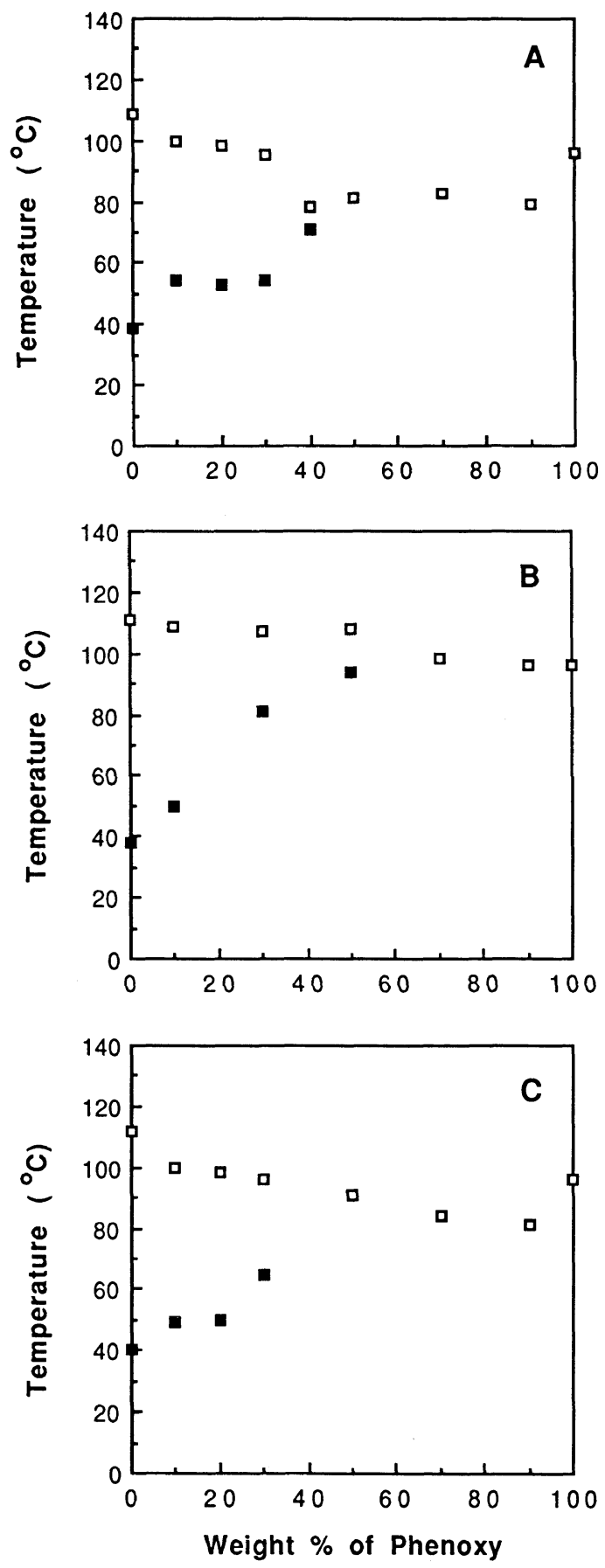

Figure 4. Composition dependence of the glass transition temperatures of ternary blends containing PBT/ PMMA ratios of 1/3(A), 1/1(B), and 3/1(C): ( $\square$ ) PBT-rich phase; ( $\square$ ) PMMA-rich phase. 
density $B$ for $\mathrm{PBT} / \mathrm{Phenoxy}$ pairs, obtained from the melting temperature deperession of PBT in PBT/Phenoxy blends, is $-2.8 \mathrm{cal}$ $\mathrm{cm}^{-3} .^{20}$ However, the interaction parameter for PMMA/Phenoxy pairs has not been reported yet.

The variation of the dynamic mechanical properties of the PBT/Phenoxy/PMMA ternaries with the Phenoxy content is shown in Figure 5. Irrespective of the PBT/PMMA ratio, two distinct $T_{\mathrm{g}}$ peaks characteristic of the main components are observed at low Phenoxy contents. At higher loading level of Phenoxy these peaks approach each other

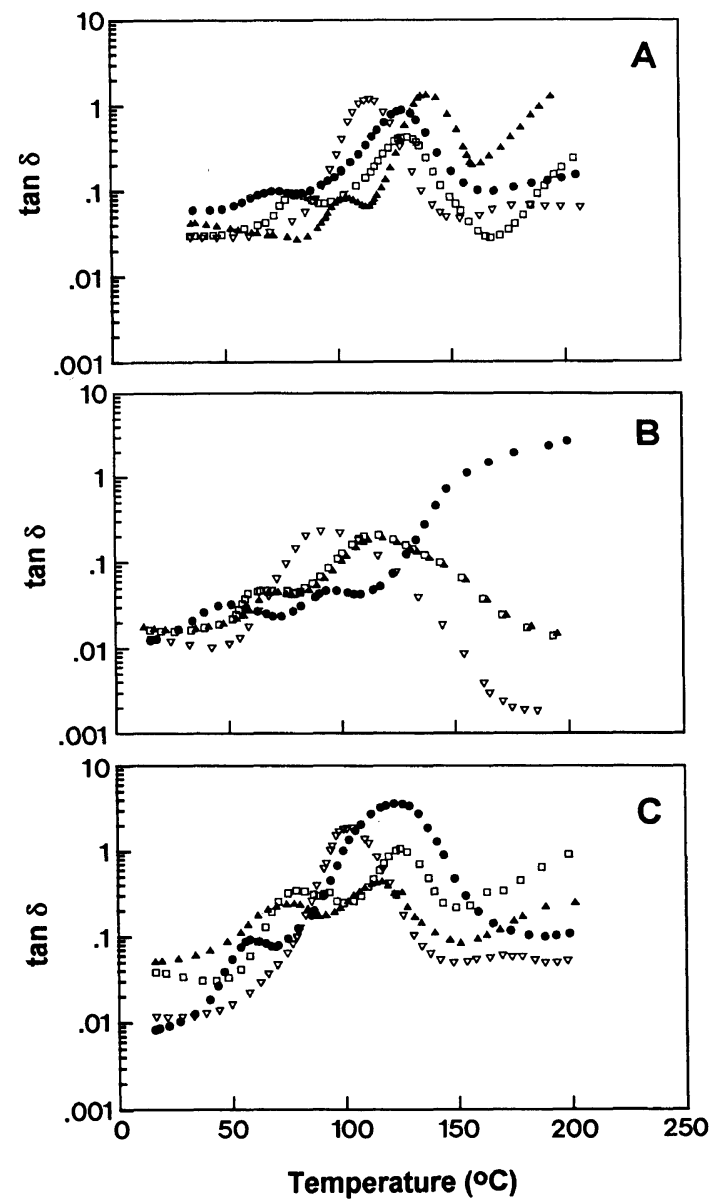

Figure 5. Temperature dependence of the dynamic loss tangent for ternary blends containing PBT/PMMA ratios of $1 / 3(\mathrm{~A}), 1 / 1(\mathrm{~B})$, and $3 / 1(\mathrm{C})$; (O) $10 \mathrm{wt} \%$; ( $\square$ ) $20 \mathrm{wt} \%$; (A) $30 \mathrm{wt} \%$; $\triangle$ ) $50 \mathrm{wt} \%$ Phenoxy added, respectively. and then coalesce. These results essentially support that the transition from two phase systems to a homogeneous single phase occurs as the Phenoxy content in the ternaries increases. The results from the dynamic mechanical analysis well corresponds to those from the thermal analysis using DSC. An increase of $\tan \delta$ at the temperature of near $200^{\circ} \mathrm{C}$ are closely related to the molecular motion within the crystalline phase of PBT, i.e., $\alpha_{\mathrm{c}}$-relaxation. ${ }^{21}$ However, the reason for an abnormal increase of $\tan \delta$ in Figure $5 \mathrm{~B}(10 \mathrm{wt} \%$ Phenoxy added $)$ is not clear at this time.

\section{Morphological Observation \\ Electron microscopy may provide a con-}
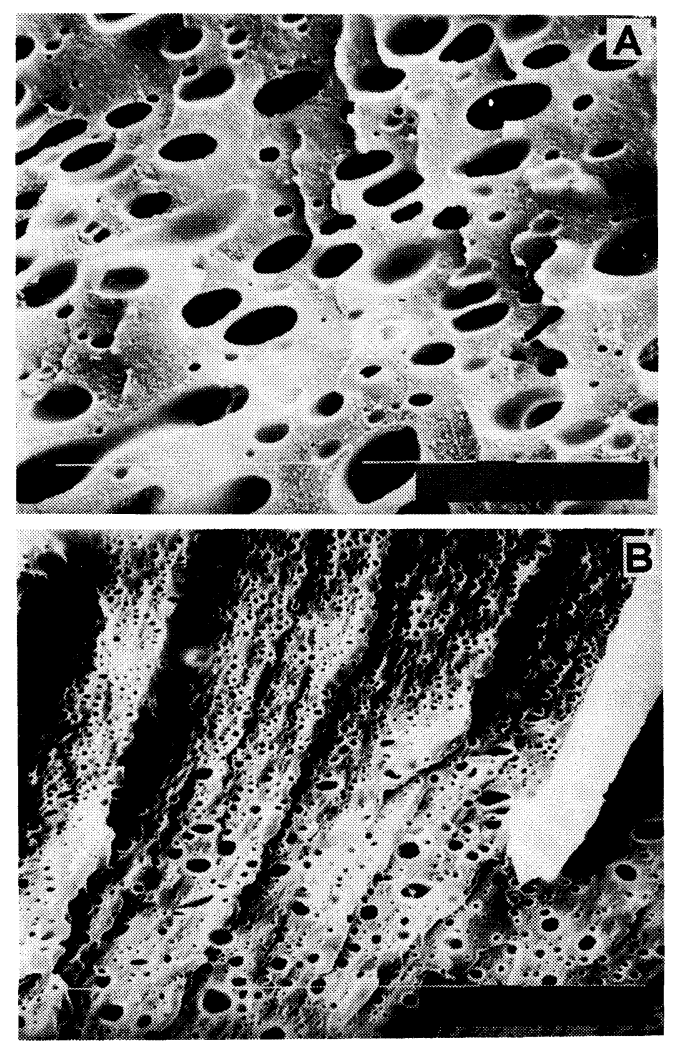

Figure 6. Scanning electron micrographs of fracture surfaces of 70/30 PBT/PMMA blends, followed by minor phase dissolution: (A) without Phenoxy; (B) 10\% Phenoxy added. 

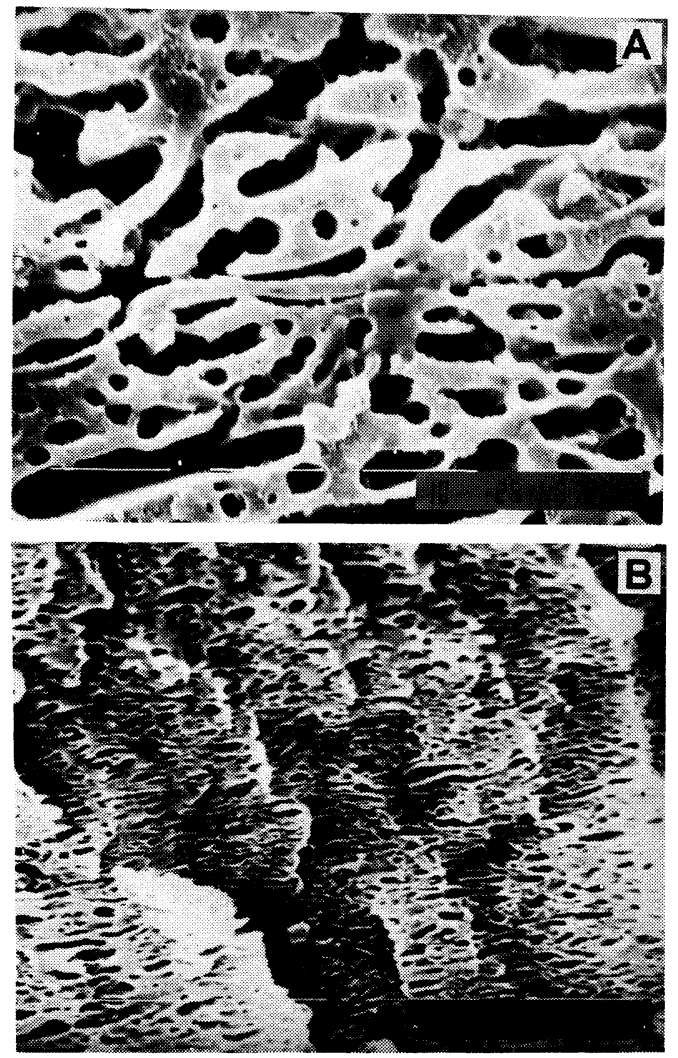

Figure 7. Scanning electron micrographs of fracture surfaces of 50/50 PBT/PMMA blends, followed by minor phase dissolution: (A) without Phenoxy; (B) 10\% Phenoxy added.

vincing evidence of the interfacial activity of the Phenoxy on the immiscible PBT/PMMA blends. Figures 6 and 7 show the morphological changes of 70/30 and 50/50 blends of PBT and PMMA upon the addition of Phenoxy, respectively. In the figures, the PMMA rich phase is extracted by formic acid. As shown in Figure 6(A) and 7(A), the blends without Phenoxy show the fractogram characteristic of immiscible blends; a large particle size, irregular shapes, and poor intefacial adhesion. When $10 \mathrm{wt} \%$ of Phenoxy is added to the blends, the morphology changed dramatically into a more regular and finer dispersion (see Figures 6(B) and 7(B)). This result suggests that Phenoxy effectively reduces the interfacial
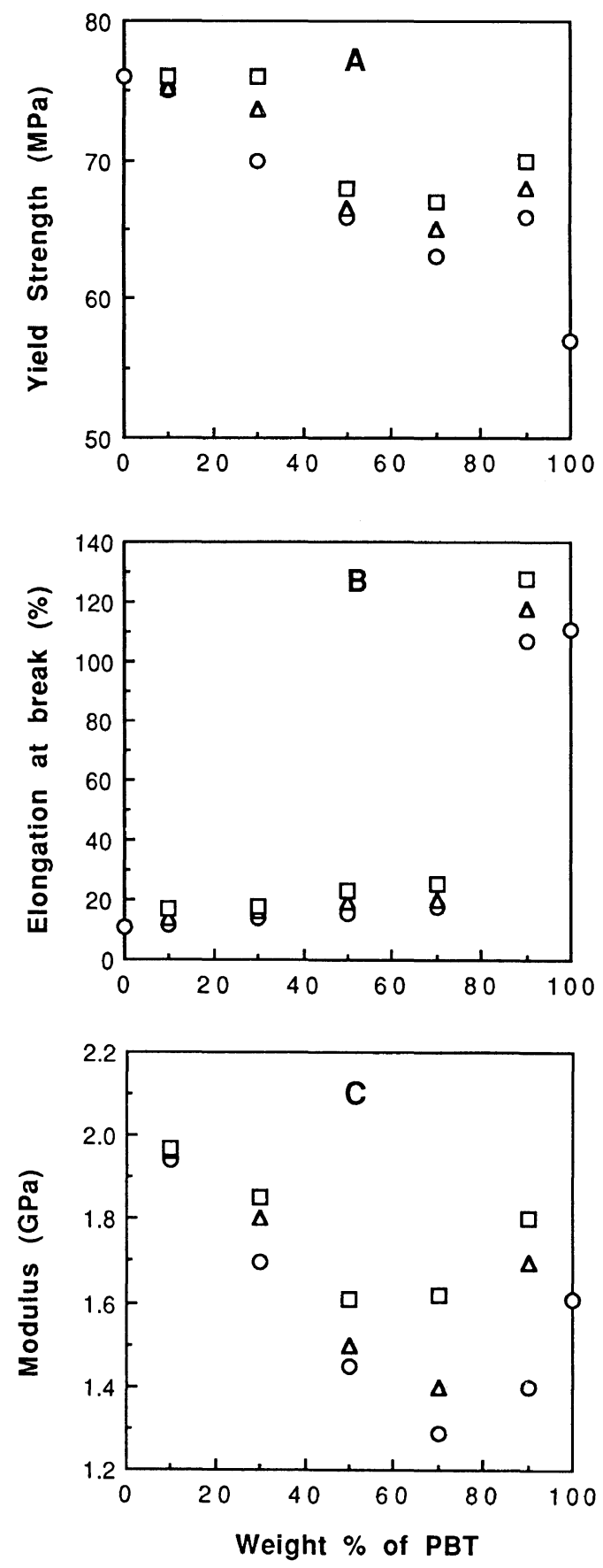

Figure 8. Yield strength (A), elongation at break (B), and tensile modulus $(\mathrm{C})$ of ternary blends as a function of weight \% of PBT: (O) without Phenoxy; $(\triangle)$ 5\% Phenoxy added; ( $\square$ ) $10 \%$ Phenoxy added. 
tension between the matrix (PBT rich phase) and the dispersed phase (PMMA rich phase).

It is generally known that the compatibilizer added to an immiscible blend should be located at the interface of two phases to play its appropriate role. However, it is not possible to ascertain whether the location of the Phenoxy in the ternaries is the interface of the two immiscible polymers, PBT and PMMA. At this time, one possible explanation is that the solubilization of a common polymer, i.e., Phenoxy, in the two phases causes the enhancement of the compatibility between the phases, resulting in the reduction of the interfacial tension.

\section{Tensile Properties}

The effect of Phenoxy on the morphological change of the PBT/PMMA blends may have something to do with the tensile properties. Figure 8 is the plots of the yield strength, elongation at break, and tensile modulus versus the PBT composition of the blends. An increase in the tensile properties is observed when the amount of Phenoxy added increases. The increase in tensile properties may come from the better interfacial adhesion between the matrix and the dispersed phase and/or the domain size reduction. Thus it is concluded that Phenoxy plays a role as a compatibilizer. However, in contrast with the morphological change an improvement in tensile properties is limited, indicating that the efficiency of Phenoxy in the compatibilization of PBT/ PMMA blends is not so dramatic. It is noteworthy that the $90 / 10$ blend of PBT and PMMA has a higher yield strength and elongation at break than the additive rule regardless of the addition of Phenoxy. This observation often occurs in the ductile/brittle blend pairs reported by Inoue et al..$^{22,23}$

\section{CONCLUSIONS}

The possibility using Phenoxy as a compatibilizer for PBT/PMMA blends is examined. It is known that Phenoxy is miscible with both PBT and PMMA. When a small amount of Phenoxy is added, the domain size of PBT/PMMA blends is dramatically reduced. As the amount of Phenoxy is increased, two $T_{\mathrm{g}}$ 's corresponding to PMMA-rich and PBTrich phases approach each other, and then coalesce. These results support that two phase systems are changed into a homogeneous single phase as the Phenoxy content in the ternaries increases. The tensile properties are increased with the Phenoxy content. This may come from the better interfacial adhesion and/or the domain size reduction, although it is not clear whether the location of Phenoxy in the ternaries is the interface of two immiscible polymers, PBT and PMMA.

Acknowledgement. The authors thank the Ministry of Education for their financial support through Advanced Materials Program (1991).

\section{REFERENCES}

1. D. R. Paul and S. Newman, Ed., "Polymer Blends," Academic Press, New York, 1978.

2. O. Olabisi, L. M. Robeson, and M. T. Shaw, "Polymer-Polymer Miscibility," Academic Press, New York, 1979.

3. P. Smith, M. Hara, and A. Eisenberg, "Current Topics in Polymer Science," Vol. II, Macmillan Publishing Co., New York, 1987, p 255.

4. D. R. Paul, "Polymer Blends," Vol. 2, D. R. Paul and S. Newman, Ed., Academic Press, New York, 1978, Chapter 12.

5. R. Fayt, R. Jerome, and P. Teyssie, "Multiphase polymers: Blends and Ionomers," L. A. Utracki and R. A. Weiss, Ed., Washington, D. C., 1989, Chapter 2.

6. S. Akiyama, Seni-i Gakkaishi, 48, P-605 (1992).

7. T. K. Kwei, H. L. Frisch, W. Radigan, and S. Vogel, Macromolecules, 10, 157 (1977).

8. Y. Y. Wang and S. A. Chen, Polym. Eng. Sci., 21, 47 (1981)

9. V. S. Shah, J. D. Keitz, D. R. Paul, and J. W. Barlow, J. Appl. Polym. Sci., 32, 3863 (1986).

10. J. I. Eguiazabal, J. J. Iruin, M. Cortazar, and G. M. Guzman, J. Appl. Polym. Sci., 32, 5945 (1986).

11. K. E. Min, J. S. Chiou, J. W. Barlow, and D. R. Paul, Polymer, 28, 1721 (1987).

12. S. N. Koklas, D. D. Sotiropoulou, J. K. Kallitsis, 
and N. K. Kalfoglou, Polymer, 32, 66 (1991).

13. W. H. Jo, Y. K. Kwon, and I. H. Kwon, Macromolecules, 24, 4708 (1991).

14. S. Krause, "Polymer Blends," Vol. 2, D. R. Paul and S. Newman, Ed., Academic Press, New York, 1978, Chapter 2.

15. L. M. Robeson and A. B. Furtek, J. Appl. Polym. Sci., 23, 645 (1979).

16. J. S. Chiou and D. R. Paul, J. Appl. Polym. Sci., 42, 279 (1991).

17. H. S. Lee, M. S. Thesis, Seoul National university, 1991.
18. M. Bosma, Gten Brinke, and T. S. Ellis, Macromolecules, 21, 1465 (1988).

19. G. ten Brinke and R. Grooten, Colloid Polym. Sci., 267, 992 (1989).

20. W. H. Jo and H. S. Lee, Kor. Polym. J., 1, 123 (1993).

21. T. Murayama, "Dynamic Mechanical Analysis of Polymeric Materials, "Elsevier Scientific Publishers Amsterdam, 1978.

22. K. K. Koo, T. Inoue, and K. Miyasaka, Polym. Eng. Sci., 25, 741 (1985).

23. J. C. Angola, Y. Fujita, T. Sakai, and T. Inoue, $J$. Appl. Polym. Sci., 26, 807 (1988). 